\title{
Real-world adherence and persistence for newly-prescribed HIV treatment: single versus multiple tablet regimen comparison among US medicaid beneficiaries
}

\author{
Joshua Cohen ${ }^{1}$, Anne Beaubrun ${ }^{2}$, Richa Bashyal ${ }^{3}$, Ahong Huang ${ }^{3 *}$, Jieni Li $^{3}$ and Onur Baser ${ }^{4,5}$
}

\begin{abstract}
Background: Once-daily, single-tablet regimens (STRs) have been associated with improved patient outcomes compared to multi-tablet regimens (MTRs). This study evaluated real world adherence and persistence of HIV antiretroviral therapy (ART), comparing STRs and MTRs.

Methods: Adult Medicaid beneficiaries (aged $\geq 18$ years) initiating ART with $\geq 2$ ART claims during the identification period (January 1, 2015-December 31, 2016) and continuous health plan enrollment for a 12-month baseline period were included. For STRs, the first ART claim date was defined as the index date; for MTRs, the prescription fill claim date for the last drug in the regimen was defined as the index date, and prescription fills were required to occur within a 5-day window. Adherence was assessed in 30-day intervals over a 6-month period, with adherence defined as having less than a 5-day gap between fills. Persistence was evaluated as median number of days on therapy and percent persistence at 12 months. Cox Proportional Hazard models were used to evaluate risk of discontinuation, controlling for baseline and clinical characteristics.
\end{abstract}

Results: A total of 1,744 (STR=1290; MTR=454) and 2409 (STR=1782; MTR=627) patients newly prescribed ART had available data concerning adherence and persistence, respectively. Average age ranged $40-42$ years. The patient population was predominantly male. Adherence assessments showed $22.7 \%$ of STR initiators were adherent to their index regimens over a 6-month period compared to $11.7 \%$ of MTR initiators. Unadjusted persistence analysis showed 36.3\% of STR initiators discontinued first-line therapy compared to 48.8\% for MTR initiators over the 2-year study period. Controlling for baseline demographic and clinical characteristics, MTR initiators had a higher risk of treatment discontinuation (hazard ratio $[H R]=1.6, \mathrm{p}<0.0001$ ). Among STRs, compared to the referent elvitegravir(EVG)/ cobicistat(COBI)/emtricitabine(FTC)/tenofovir alafenamide(TAF), risk of discontinuation was higher for efavirenz(EFV)/ FTC/tenofovir disoproxil fumarate(TDF) (HR=3.6, $p<0.0001)$, EVG/COBI/FTC/TDF (HR=2.8, $p<0.0001)$, and abacavir $(\mathrm{ABC}) /$ lamivudine $(3 \mathrm{TC}) /$ dolutegravir $(\mathrm{DTG})(\mathrm{HR}=1.8, \mathrm{p}=0.004)$. Among backbones, $\mathrm{FTC} / \mathrm{TAF}$ was associated with lower risk of discontinuation than FTC/TDF ( $H R=4.4, p<0.0001)$ and $A B C / 3 T C(H R=2.2, p<0.0001)$.

Conclusions: Among patients newly prescribed ART, STR initiators were significantly less likely to discontinue therapy and had greater adherence and persistence compared to MTR initiators. Regimens containing FTC/TAF as a backbone had higher persistence than those consisting of other backbones.

*Correspondence: ahuang@statinmed.com

3 STATinMED Research, Plano, TX, USA

Full list of author information is available at the end of the article

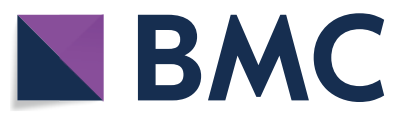

(c) The Author(s) 2020. This article is licensed under a Creative Commons Attribution 4.0 International License, which permits use, sharing, adaptation, distribution and reproduction in any medium or format, as long as you give appropriate credit to the original author(s) and the source, provide a link to the Creative Commons licence, and indicate if changes were made. The images or other third party material in this article are included in the article's Creative Commons licence, unless indicated otherwise in a credit line to the material. If material is not included in the article's Creative Commons licence and your intended use is not permitted by statutory regulation or exceeds the permitted use, you will need to obtain permission directly from the copyright holder. To view a copy of this licence, visit http://creativeco mmons.org/licenses/by/4.0/. The Creative Commons Public Domain Dedication waiver (http://creativecommons.org/publicdomain/ zero/1.0/) applies to the data made available in this article, unless otherwise stated in a credit line to the data. 
Keywords: HIV, Antiretroviral therapy, Adherence, Persistence, Discontinuation

\section{Background}

At the end of 2015, 1.1 million people aged $\geq 13$ years were living with human immunodeficiency virus (HIV) in the United States [1]. While estimated annual HIV infections in the United States have declined by $10 \%$ from 2010 to 2014 [1], the condition remains a serious public health concern given the burden it imposes on patients and the health care system.

HIV treatment typically includes a combination of antiretroviral therapy (ART) regimens to prevent HIV disease progression and transmission [2]. ART has brought about a substantial decrease in mortality due to HIV infection, changing it from a rapidly lethal disease into a chronic manageable condition [3]. In fact, the use of ART has significantly shown an improvement in the life-expectancy and quality of life (QoL) among people infected with HIV $[4,5]$. Moreover, early initiation of ART has shown improvement in clinical outcomes and reduction in sexual transmission of HIV through viral suppression [5]. The Department of Health and Human Services (DHHS) panel on antiretroviral guidelines for adults and adolescents also recommends immediate initiation of ART for all people living with HIV, regardless of CD4 count, to reduce the morbidity and mortality associated with HIV infection [6]. These guidelines recommend initiating ART in treatment naïve patients with a regimen consisting of two nucleoside reverse transcriptase inhibitors (NRTIs) along with a third drug: preferably an integrase strand transfer inhibitor (INSTI), with nonnucleoside reverse transcriptase inhibitors (NNRTI) or boosted protease inhibitors (PI) as alternatives to INSTIs [5-7].

Combination ART was initially characterized by high pill burden and multiple daily doses [8-10]. Over the past two decades, more potent, more convenient, and less-toxic ART regimens have been developed; treatment regimens of up to 20 pills per day have been largely replaced by once-daily, single-tablet regimens (STRs) [10, 11]. As of March 2016, six STRs-elvitegravir (EVG)/ cobicistat (COBI)/emtricitabine (FTC)/tenofovir alafenamide fumarate (TAF), EVG/COBI/FTC/tenofovir disoproxil fumarate (TDF), dolutegravir (DTG)/abacavir $(\mathrm{ABC}) / /$ lamivudine (3TC), FTC/rilpivirine (RPV)/TAF, FTC/RPV/TDF, and efavirenz (EFV)/FTC/TDF-had been approved by the US Food and Drug Administration for HIV treatment [12]. STRs are single-dose units administered once-daily, whereas multi-tablet regimens (MTRs) require multiple dosing units per day [4]. STRs may improve adherence, thus resulting in greater efficacy, reduced risk of virologic failure, and prevention of the emergence of drug resistance [13, 14]. The decision to prescribe STRs vs MTRs is based to a large extent on patient and clinician preference as well as, in some instances, medication cost and positioning of products on payer formularies $[15,16]$. Moreover, HIV infection requires a high level of adherence to achieve viral suppression, presenting a challenge for HIV management, particularly among patients who face barriers such as limited provider and pharmacy services, low social support, and substance use $[17,18]$. Reducing pill burden and structural barriers may therefore help patients achieve increased adherence and improved health outcomes.

Prior research suggests that adherence and persistence may be higher among patients treated with STRs compared with those treated with MTRs [13, 19]. However, with the advent of new treatment options with greater effectiveness and tolerability, the extent to which adherence and persistence varies between and within STRs and MTRs has not been fully investigated. Amongst third agents, INSTIs are the most preferred as evident in studies that showed it be superior or equivalent to other third agents in safety and efficiency. In addition, it is reported that INSTIs are more tolerable to patients, in turn reducing discontinuation rates [20-23]. However, for patients that are at higher risk of non-adherence, PIs as the third agent would be most appropriate because of their genetic barrier to resistance [24]. For backbones, tenofovir-containing nucleoside has shown higher safety and tolerability then abacavir-lamivudine [25]. In addition, tenofovir/ emtricitabine has been found to have a lower rate of discontinuation than co-formulated abacavir/lamivudine [20]. Hence, this retrospective claims-based study was conducted with an aim to assess real world adherence and persistence for newly prescribed HIV treatment comparing STRs versus MTRs, backbones, and third agents using the Truven Health Medicaid database.

\section{Methods}

\section{Data source}

This retrospective real-world study utilized data from the Truven Health Medicaid database from January 1, 2014 through December 31, 2016 (study period), with an approximately 6 months lag time. The Truven Health Medicaid Database contains medical, surgical, and prescription drug claims for more than 44 million Medicaid enrollees from multiple states. The database includes records of inpatient services, inpatient admissions, 
outpatient services, and prescription drug claims as well as information about long-term and other medical care. Data on eligibility (by month), service, and provider type are also included. In addition to standard demographic variables including age, gender, and race, the database also included variables more specific for Medicaid populations including aid category (e.g., blind or disabled, medicare eligible).

\section{Study population}

Adult patients (aged $\geq 18$ years) initiating ART after one pre-index year of not receiving ART (i.e. presumably beginning first-line ART for the majority of patients) with $\geq 2$ claims for an ART of interest (Table 1) during the identification period (January 1, 2015 through December 31, 2016) were included. For STRs, the first ART claim date during the identification period was designated as the index date. For MTRs, the prescription fill claim date of the last drug in the regimen was identified as the index date. MTRs consisting of two drug claims, both therapies in the regimen, were required to have been filled within a 5-day window. For MTRs with a boosted agent (ritonavir or COBI), the boosted agent was required to have been filled within 5 days of the second drug in the regimen. For example, for an FTC/ TDF + darunavir (DRV) regimen boosted with COBI, the DRV prescription was required to have been filled within 5 days of FTC/TDF, and the COBI prescription was filled within 5 days of DRV. Patients prescribed any other ART outside of the common, guideline-recommended ARTs of interest, or those with an inappropriate MTR regimen, were excluded from the study. Eligible patients had continuous health plan enrollment in the Truven Medicaid population for a 12-month baseline period. If patients lost Medicaid coverage within 6 months of follow-up, they were excluded from the study. Patients were selected based on two enrollment criteria: (1) assess adherence among patients with $\geq 6$-month follow-up period, and (2) assess persistence among patients with a follow-up period through the earlier of either the end of continuous enrollment or end of the study period. Patients who died during the follow-up period were not included in the study. Eligible patients were further stratified into STR and MTR cohorts based on their index prescription claim. STR and MTR initiators were further sub-stratified based on the individual STR drug and MTR regimen.

\section{Demographic and baseline clinical characteristics}

Patient demographics including age, gender, race, and insurance type were assessed. Additionally, clinical characteristics including pre-index medication use (i.e., antihypertensive, antidiabetics, anticoagulants, antiarrhythmic drugs, lipid-lowering therapy, antibiotics, and respiratory drugs for lower and upper respiratory infections), number of unique medications on index date except ART, Deyo-modified Charlson comorbidity index (CCI) score, and baseline individual comorbidities (i.e., central nervous system toxicity, gastrointestinal symptoms, mental disorders, AIDS-defining condition, substance abuse, jaundice, dyslipidemia, diabetes, chronic kidney disease, cardiovascular disease, and myocardial infarction; recognized using International Classification of Diseases, 9th Revision, Clinical Modification [ICD-9-CM] codes) were assessed. All ICD-9-CM codes

Table 1 Antiretroviral therapies of interest

\begin{tabular}{|c|c|c|c|}
\hline \multicolumn{2}{|l|}{ STR } & \multicolumn{2}{|l|}{ MTR } \\
\hline Brand name & Components & Brand name (Regimen) & Components \\
\hline Genvoya ${ }^{\circledR}$ & EVG/COBI/FTC/TAF & Epzicom ${ }^{\circledR}+$ Prezista $^{\circledR}$ boosted with ritonavir & $\mathrm{ABC} / 3 \mathrm{TC}+\mathrm{DRV} / \mathrm{r}$ \\
\hline Stribild ${ }^{\circledR}$ & EVG/COBI/FTC/TDF & Epzicom ${ }^{\circledR}+$ Prezista ${ }^{\circledR}$ boosted with COBI & $\mathrm{ABC} / 3 \mathrm{TC}+\mathrm{DRV} / \mathrm{C}$ \\
\hline Triumeq ${ }^{\circledR}$ & ABC/3TC/DTG & Truvada $^{\circledR}+$ Tivicay $^{\circledR}$ & $\mathrm{FTC} / \mathrm{TDF}+\mathrm{DTG}$ \\
\hline Odefsey ${ }^{\circledR}$ & $\mathrm{RPV} / \mathrm{FTC} / \mathrm{TAF}$ & Descovy ${ }^{\circledR}+$ Tivicay $^{\circledR}$ & $\mathrm{FTC} / \mathrm{TAF}+\mathrm{DTG}$ \\
\hline Complera $^{\circledR}$ & RPV/FTC/TDF & Truvada ${ }^{\circledR}+$ Prezista ${ }^{\circledR}$ boosted with ritonavir & $\mathrm{FTC} / \mathrm{TDF}+\mathrm{DRV} / \mathrm{r}$ \\
\hline \multirow[t]{7}{*}{ Atripla ${ }^{\circledR}$} & EFV/FTC/TDF & Truvada $^{\circledR}+$ Prezista $^{\circledR}$ boosted with COBI & $\mathrm{FTC} / \mathrm{TDF}+\mathrm{DRV} / \mathrm{C}$ \\
\hline & & Descovy ${ }^{\circledR}+$ Prezista ${ }^{\circledR}$ boosted with ritonavir & $\mathrm{FTC} / \mathrm{TAF}+\mathrm{DRV} / \mathrm{r}$ \\
\hline & & Descovy ${ }^{\circledR}+$ Prezista ${ }^{\circledR}$ boosted with COBI & $\mathrm{FTC} / \mathrm{TAF}+\mathrm{DRV} / \mathrm{C}$ \\
\hline & & Truvada ${ }^{\circledR}+$ Reyataz ${ }^{\circledR}$ boosted with ritonavir & $\mathrm{FTC} / \mathrm{TDF}+\mathrm{ATV} / \mathrm{r}$ \\
\hline & & Truvada $^{\circledR}+$ Reyataz $^{\circledR}$ boosted with COBI & $\mathrm{FTC} / \mathrm{TDF}+\mathrm{ATV} / \mathrm{C}$ \\
\hline & & Descovy ${ }^{\circledR}+$ Reyataz $^{\circledR}$ boosted with ritonavir & $\mathrm{FTC} / \mathrm{TAF}+\mathrm{ATV} / \mathrm{r}$ \\
\hline & & Descovy ${ }^{\circledR}+$ Reyataz ${ }^{\circledR}$ boosted with COBI & $\mathrm{FTC} / \mathrm{TAF}+\mathrm{ATV} / \mathrm{C}$ \\
\hline
\end{tabular}

$3 T C$ lamivudine, $A B C$ abacavir, ATV atazanavir, ATV/c atazanavir boosted with cobicistat, $A T V / r$ atazanavir boosted with ritonavir, COBI cobicistat, DRV darunavir, DRV/r darunavir boosted with ritonavir, DRV/c darunavir boosted with cobicistat, DTG dolutegravir, EFV efavirenz, EVG elvitegravir, FTC emtricitabine, RPV rilpivirine, TAF tenofovir alafenamide fumarate, TDF tenofovir disoproxil fumarate 
were mapped to ICD-10-CM codes based on the General Equivalence Mappings published by the Centers for Medicare \& Medicaid Services (CMS) [26].

\section{Outcome measures}

Outcome measures, including adherence and persistence during the follow-up period were measured. In HIV, a high level of adherence to ART is required for viral suppression [13]. However, thresholds for categorizing "adherent" versus "non-adherent" differ across studies (e.g. taking $80 \%$ of prescribed [27], to taking $95 \%-100 \%$ of prescribed $[28,29])$, and studies further differ in measures used for assessing adherence (e.g. self-report, proportion of days covered) and study time periods over which adherence is measured. In this study, adherence to first-line STRs and MTRs was categorized as adherent/ non-adherent over the 6-month follow-up period, and was also assessed on a month-by-month basis (30-day intervals). Based on prior adherence measures assessing missed doses over 4-7 day periods [29-31], adherence was defined as $\leq 5$-day gap between successive fills for patients initiating STRs, while non-adherence was defined as a $>5$-day gap between successive fills, measured from the end of days' supply of one fill and the claim date of the following fill during the 6-month follow-up period. Among patients who initiated an MTR, adherence was defined as $\leq 5$ days in which one or more drugs in the regimen were not on hand according to prescription days of supply; non-adherence was defined as $>5$ days in which one or more drugs in the regimen was not on hand. Among non-adherent patients, the refill gap (days) and proportion of patients with a cumulative refill gap was also calculated. Sensitivity analyses were also performed by using different gap thresholds $(\leq 7$ and $\leq 14$ days) to evaluate the impact of expanding the gap window on adherence to STR.

Persistence for HIV treatments was compared between STRs versus MTRs, backbones, and third agents where persistence was measured from the index regimen start date until the start of the first 90-day gap between prescription fills or the end of the enrollment. Patients were considered to have discontinued first-line therapy if a gap of $\geq 90$ days between fills was observed. Patients who restarted therapy after $a \geq 90$-day gap remained classified as discontinued, as restarts were not captured in the analysis. MTR initiators were required to remain on all therapies in the initial regimen to be considered persistent. Among MTR initiators, a gap of $\geq 90$ days for any drug in the regimen was considered discontinuation of that regimen. The proportion of patients who discontinued their first-line therapy, time to discontinuation, and the proportion of patients with 12 months of persistence were also measured. Additionally, persistence was assessed as the risk of treatment discontinuation among different treatment cohorts.

\section{Statistical analysis}

All study variables, including baseline demographics and clinical characteristics, as well as outcome variables (i.e., adherence and persistence) were first examined descriptively. For continuous variables such as persistence measures, mean, median, and standard deviations were generated. For categorical variables, counts (frequencies) and percentages were reported.

Overall time to discontinuation of first-line ART for STRs and MTRs was assessed via Kaplan-Meier curves. Log-rank tests were used to evaluate statistical differences between treatment discontinuation curves. To assess the factors associated with risk of treatment discontinuation for each regimen, a multivariable Cox proportional hazard model was constructed. Covariates included in the multivariable-adjusted model comprised age group, gender, race, insurance type, CCI score, baseline individual comorbidities (more specific than CCI comorbidities), pre-index medication use, and the number of unique medications on index date. All of the analyses were conducted using $\mathrm{SAS}^{\circledR}$ statistical software (Version 9.3, SAS Institute, Cary, North Carolina, 2012).

\section{Results}

For the adherence study, 1744 patients met inclusion criteria, of whom 1290 (74.0\%) initiated STRs and 454 (26\%) initiated MTRs. For the persistence study, 2409 patients met inclusion criteria, of whom 1782 (74.0\%) initiated STRs and 627 (26.0\%) initiated MTRs. Patients on STRs and MTRs were further stratified by specific ARTs to compare persistence within STRs and within MTRs (Fig. 1).

\section{Patient population characteristics}

The average age of newly treated HIV patients was 40 (persistence sample) to 41 (adherence sample). The adherence study included 1744 patients, most (71.4\%) of whom were aged 18-49 years, male (56.5\%), black (61.0\%), and were enrolled in a comprehensive insurance plan (74.4\%). Among patients in the adherence sample, pre-index medication use was highest for respiratory drugs $(54.9 \%)$ and antibiotics $(43.5 \%)$; the most common comorbidities at baseline were mental health disorders (56.5\%), substance abuse (41.5\%), and central nervous system toxicity (40.9\%). Mean CCI score during the baseline period was $4.2 \pm 3.4$. Patients taking STRs and MTRs had similar demographic and clinical characteristics (Table 2). Among the 2409 patients included in the persistence analysis, demographic and clinical 


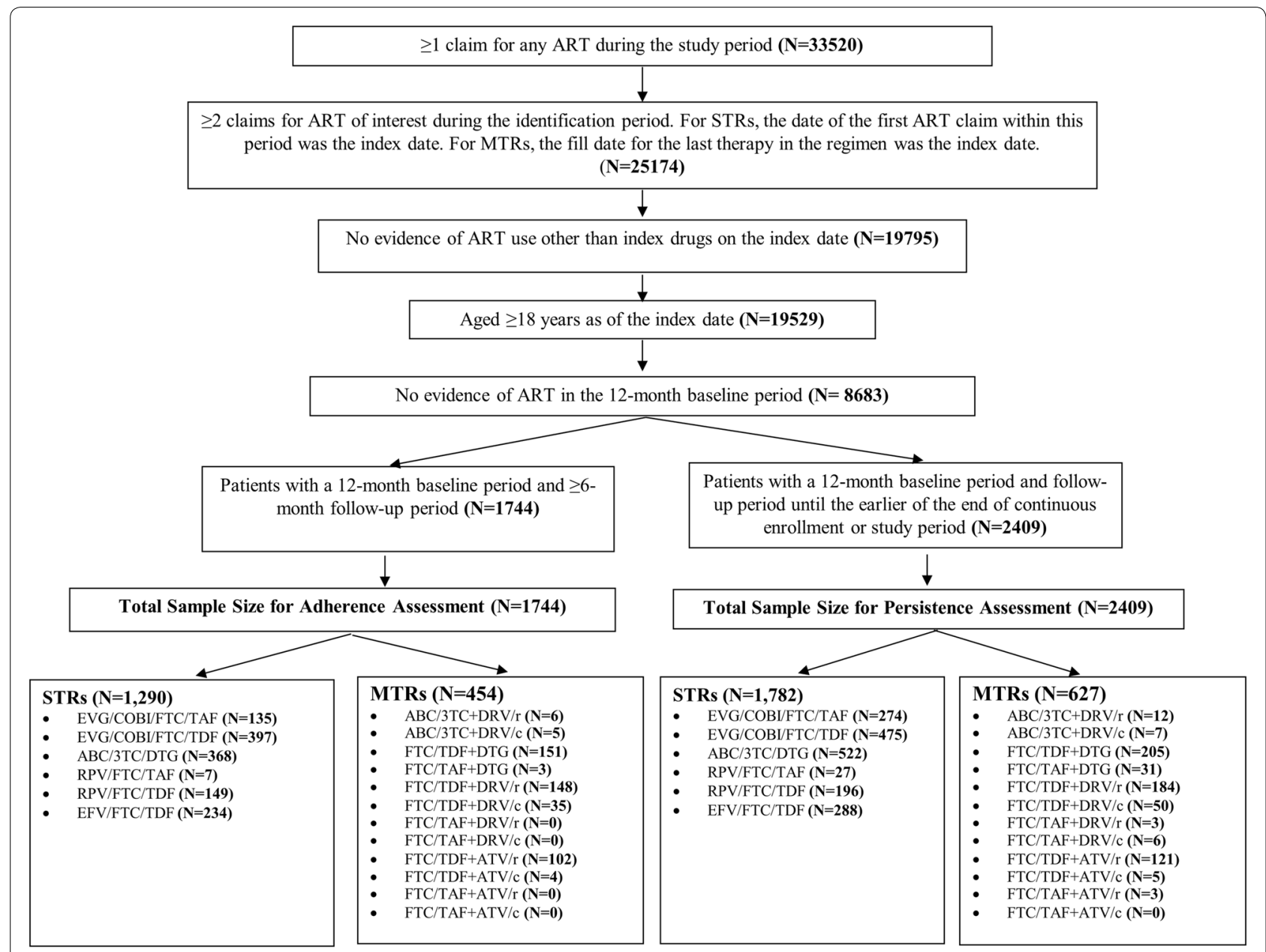

Fig. 1 Study population and cohorts. 3TC lamivudine, ABC abacavir, ATV atazanavir, ATV/C atazanavir boosted with cobicistat, ATV/r atazanavir boosted with ritonavir, COBI cobicistat, DRV darunavir, DRV/r darunavir boosted with ritonavir, DRV/c: darunavir boosted with cobicistat, DTG: dolutegravir; EFV efavirenz, EVG elvitegravir, FTC emtricitabine, RPV rilpivirine, TAF tenofovir alafenamide fumarate, TDF tenofovir disoproxil fumarate

characteristics were similar to patients included in the adherence cohort (Table 2).

\section{Treatment adherence}

Among patients who initiated STRs, nearly all the patients (99.7\%) during the post-index period of 1-30 days were adherent, defined as a gap of $\leq 5$ days between successive fills. However, adherence declined sharply by $38.4 \%$ during the post-index period of 31-60 days, corresponding to when patients would have had to refill a 30-day supply. Thereafter, a gradual decline was observed at each post-index period. Similarly, among patients who initiated MTRs, nearly all patients (98.9\%) during the post-index period of 1-30 days were adherent, defined as having a gap of $\leq 5$ days between successive fills for any drug in the regimen. Adherence declined by roughly $45.0 \%$ during the post-index period of 31-60 days, and decreased gradually at each post-index period afterwards. The proportion of adherent patients at each post-index period was higher among patients on STRs as compared to patients prescribed MTRs (Fig. 2). Likewise, during the post-index period of 1-180 days, the proportion of adherent patients was higher among patients who were prescribed STRs (22.7\%) compared to MTRs (11.7\%). Over 6-months of follow-up, 36.3\% of patients initiating STRs and $48.8 \%$ of patients initiating MTRs discontinued therapy.

Among patients on STRs who were non-adherent, the mean refill gap at each post-index time interval ranged from 22-24 days with a cumulative mean refill gap of 71 days during the overall 6 -month period. Likewise, among patients prescribed MTRs, the mean refill gap at each post-index time interval ranged from 18-25 days, with a cumulative mean refill gap of 81 days during the overall 6-month follow-up period. A greater proportion of patients prescribed MTRs had a cumulative refill gap 
Table 2 Baseline demographic and clinical characteristics of Medicaid beneficiaries newly prescribed HIV treatment

\begin{tabular}{|c|c|c|c|c|c|c|}
\hline \multirow{3}{*}{$\begin{array}{l}\text { Baseline demographics and clinical } \\
\text { characteristics }\end{array}$} & \multicolumn{3}{|c|}{ Adherence assessment population } & \multicolumn{3}{|c|}{ Persistence assessment population } \\
\hline & \multirow{2}{*}{$\begin{array}{l}\begin{array}{l}\text { Overall } \\
\text { patients } \\
(\mathrm{N}=1744)\end{array} \\
\mathrm{N}(\%)\end{array}$} & \multirow{2}{*}{$\begin{array}{l}\text { STRs }(N=1290) \\
N(\%)\end{array}$} & \multirow{2}{*}{$\begin{array}{l}\text { MTRs }(\mathrm{N}=454) \\
\mathrm{N}(\%)\end{array}$} & \multirow{2}{*}{$\begin{array}{l}\begin{array}{l}\text { Overall } \\
\text { patients } \\
(\mathrm{N}=2409) \\
\mathrm{N}(\%)\end{array} \\
\end{array}$} & \multirow{2}{*}{$\begin{array}{l}\text { STRs }(N=1782) \\
N(\%)\end{array}$} & \multirow{2}{*}{$\begin{array}{l}\text { MTRs }(\mathrm{N}=627) \\
\mathrm{N}(\%)\end{array}$} \\
\hline & & & & & & \\
\hline Mean age (mean $\pm \mathrm{SD}$ ) & $41.0 \pm 12.9$ & $40.0 \pm 13.3$ & $42.0 \pm 11.8$ & $40.1 \pm 13.1$ & $40.0 \pm 13.5$ & $41.0 \pm 12.0$ \\
\hline \multicolumn{7}{|l|}{ Age group (years) } \\
\hline $18-34$ & $631(36.2 \%)$ & $493(38.2 \%)$ & $138(30.4 \%)$ & $918(38.1 \%)$ & $714(40.1 \%)$ & $204(32.5 \%)$ \\
\hline $35-49$ & $614(35.2 \%)$ & $432(33.5 \%)$ & $182(40.1 \%)$ & $805(33.4 \%)$ & $559(31.4 \%)$ & $246(39.2 \%)$ \\
\hline $50-64$ & $468(26.8 \%)$ & $338(26.2 \%)$ & $130(26.8 \%)$ & $646(26.8 \%)$ & $473(26.5 \%)$ & $173(27.6 \%)$ \\
\hline$\geq 65$ & $31(1.8 \%)$ & $27(2.1 \%)$ & $4(0.9 \%)$ & $40(1.7 \%)$ & $36(2.0 \%)$ & $4(0.6 \%)$ \\
\hline \multicolumn{7}{|l|}{ Gender } \\
\hline Male & $986(56.5 \%)$ & $741(57.4 \%)$ & $245(54.0 \%)$ & $1353(56.2 \%)$ & $1026(57.6 \%)$ & $327(52.2 \%)$ \\
\hline Female & $758(43.5 \%)$ & $549(42.6 \%)$ & $209(46.0 \%)$ & $1056(43.8 \%)$ & $756(42.4 \%)$ & $300(47.8 \%)$ \\
\hline \multicolumn{7}{|l|}{ Race } \\
\hline White & $350(20.1 \%)$ & $270(20.9 \%)$ & $80(17.6 \%)$ & $472(19.6 \%)$ & $358(20.1 \%)$ & $114(18.2 \%)$ \\
\hline Black & 1064 (61.0\%) & $779(60.4 \%)$ & $285(62.8 \%)$ & $1460(60.6 \%)$ & 1078 (60.5\%) & $382(60.9 \%)$ \\
\hline Hispanic & $26(1.5 \%)$ & $18(1.4 \%)$ & $8(1.8 \%)$ & $37(1.6 \%)$ & $26(1.5 \%)$ & $11(1.8 \%)$ \\
\hline Other & $304(17.4 \%)$ & $223(17.3 \%)$ & $81(17.8 \%)$ & $440(18.3 \%)$ & $320(18.0 \%)$ & $120(19.1 \%)$ \\
\hline \multicolumn{7}{|l|}{ Insurance type } \\
\hline $\mathrm{HMO}$ & $445(25.5 \%)$ & $342(26.5 \%)$ & $103(22.7 \%)$ & $635(26.4 \%)$ & $480(26.9 \%)$ & $155(24.7 \%)$ \\
\hline COMP & $1298(74.4 \%)$ & $948(73.5 \%)$ & $350(77.1 \%)$ & $1773(73.6 \%)$ & $1302(73.1 \%)$ & $471(75.1 \%)$ \\
\hline \multicolumn{7}{|l|}{ Pre-index medication use } \\
\hline Antihypertensive & $439(25.2 \%)$ & $329(25.5 \%)$ & $110(24.2 \%)$ & $567(23.5 \%)$ & $425(23.8 \%)$ & $142(22.6 \%)$ \\
\hline Antidiabetics & $106(6.1 \%)$ & $83(6.4 \%)$ & $23(5.1 \%)$ & $143(5.9 \%)$ & $107(6.0 \%)$ & $36(5.7 \%)$ \\
\hline Metformin & $67(3.8 \%)$ & $54(4.2 \%)$ & $13(2.9 \%)$ & $86(3.6 \%)$ & $68(3.8 \%)$ & $18(2.9 \%)$ \\
\hline Metformin-combination & $4(0.2 \%)$ & $3(0.2 \%)$ & $1(0.2 \%)$ & $5(0.2 \%)$ & $3(0.2 \%)$ & $2(0.3 \%)$ \\
\hline Non-insulin therapy & $78(4.5 \%)$ & $63(4.9 \%)$ & $15(3.3 \%)$ & $101(4.2 \%)$ & $80(4.5 \%)$ & $21(3.3 \%)$ \\
\hline Insulin & $43(2.5 \%)$ & $32(2.5 \%)$ & $11(2.4 \%)$ & $59(2.5 \%)$ & $43(2.4 \%)$ & $16(2.6 \%)$ \\
\hline Anticoagulants & $102(5.9 \%)$ & $77(6.0 \%)$ & $25(5.5 \%)$ & $133(5.5 \%)$ & 101 (5.7\%) & $32(5.1 \%)$ \\
\hline Antiarrhythmic drugs & $1(0.1 \%)$ & $1(0.1 \%)$ & $0(0.0 \%)$ & $1(0.04 \%)$ & $1(0.1 \%)$ & $0(0.0 \%)$ \\
\hline Lipid-lowering therapy & 150 (8.6\%) & $111(8.6 \%)$ & $39(8.6 \%)$ & 193 (8.0\%) & 143 (8.0\%) & $50(8.0 \%)$ \\
\hline Statin & 148 (8.5\%) & $110(8.5 \%)$ & $38(8.4 \%)$ & 191 (7.9\%) & $142(8.0 \%)$ & $49(7.8 \%)$ \\
\hline Ezetimibe & $3(0.2 \%)$ & $2(0.2 \%)$ & $1(0.2 \%)$ & $3(0.1 \%)$ & $2(0.1 \%)$ & $1(0.2 \%)$ \\
\hline Statin/ezetimibe & $1(0.1 \%)$ & $1(0.1 \%)$ & $0(0.0 \%)$ & $1(0.04 \%)$ & $1(0.1 \%)$ & $0(0.0 \%)$ \\
\hline PCSK9 & & $0(0.0 \%)$ & $0(0.0 \%)$ & $0(0.0 \%)$ & $0(0.0 \%)$ & $1(0.0 \%)$ \\
\hline Antibiotics & $759(43.5 \%)$ & $584(45.3 \%)$ & $175(38.5 \%)$ & 1068 (44.3\%) & $810(45.5 \%)$ & $258(41.1 \%)$ \\
\hline Respiratory drugs ${ }^{a}$ & $958(54.9 \%)$ & $735(57.0 \%)$ & $223(49.1 \%)$ & $1353(56.2 \%)$ & 1029 (57.7\%) & $324(51.7 \%)$ \\
\hline $\begin{array}{l}\text { Number of unique medications on index } \\
\text { date besides ART (mean } \pm \text { SD) }\end{array}$ & $1.0 \pm 1.9$ & $0.9 \pm 1.8$ & $1.3 \pm 2.1$ & $1.0 \pm 2.0$ & $1.0 \pm 1.9$ & $1.3 \pm 2.3$ \\
\hline Deyo-modified CCI score (mean \pm SD) & $4.2 \pm 3.4$ & $4.1 \pm 3.4$ & $4.4 \pm 3.4$ & $3.4 \pm 3.5$ & $3.4 \pm 3.5$ & $3.6 \pm 3.5$ \\
\hline \multicolumn{7}{|l|}{ Baseline clinical comorbidities } \\
\hline Central nervous system toxicity & $714(40.9 \%)$ & $530(41.1 \%)$ & $184(40.5 \%)$ & $811(33.7 \%)$ & $598(33.6 \%)$ & $213(34.0 \%)$ \\
\hline Gastrointestinal symptoms & $74(4.2 \%)$ & $55(4.3 \%)$ & $19(4.2 \%)$ & $81(3.7 \%)$ & $60(3.4 \%)$ & $21(3.3 \%)$ \\
\hline Mental disorders & $986(56.5 \%)$ & $732(56.7 \%)$ & $254(55.9 \%)$ & $1134(47.1 \%)$ & $835(46.9 \%)$ & $299(47.7 \%)$ \\
\hline AIDS-defining condition & $118(6.8 \%)$ & $79(6.1 \%)$ & $39(8.6 \%)$ & $124(5.2 \%)$ & $82(4.6 \%)$ & $42(6.7 \%)$ \\
\hline Substance abuse & $724(41.5 \%)$ & $522(40.5 \%)$ & $202(44.5 \%)$ & $827(34.3 \%)$ & $591(33.2 \%)$ & $236(37.6 \%)$ \\
\hline Jaundice & $9(0.5 \%)$ & $6(0.5 \%)$ & $3(0.7 \%)$ & $9(0.4 \%)$ & $6(0.3 \%)$ & $3(0.5 \%)$ \\
\hline Dyslipidemia & $251(14.4 \%)$ & $193(15.0 \%)$ & $58(12.8 \%)$ & $270(11.2 \%)$ & 209 (11.7\%) & 61 (9.7\%) \\
\hline Diabetes & 149 (8.5\%) & 115 (8.9\%) & 34 (7.5\%) & 172 (7.1\%) & $131(7.4 \%)$ & 41 (6.5\%) \\
\hline
\end{tabular}


Table 2 (continued)

\begin{tabular}{|c|c|c|c|c|c|c|}
\hline \multirow{3}{*}{$\begin{array}{l}\text { Baseline demographics and clinical } \\
\text { characteristics }\end{array}$} & \multicolumn{3}{|c|}{ Adherence assessment population } & \multicolumn{3}{|c|}{ Persistence assessment population } \\
\hline & $\begin{array}{l}\text { Overall } \\
\text { patients } \\
(\mathrm{N}=1744)\end{array}$ & STRs $(N=1290)$ & MTRs $(\mathrm{N}=454)$ & $\begin{array}{l}\text { Overall } \\
\text { patients } \\
(\mathrm{N}=2409)\end{array}$ & STRs $(N=1782)$ & MTRs $(\mathrm{N}=627)$ \\
\hline & $\mathrm{N}(\%)$ & $\mathrm{N}(\%)$ & $\mathrm{N}(\%)$ & $\mathrm{N}(\%)$ & $\mathrm{N}(\%)$ & $\mathrm{N}(\%)$ \\
\hline Chronic kidney disease & $58(3.3 \%)$ & $42(3.3 \%)$ & $16(3.5 \%)$ & $62(2.6 \%)$ & $46(2.6 \%)$ & $16(2.6 \%)$ \\
\hline Cardiovascular disease & $562(32.2 \%)$ & $415(32.2 \%)$ & $147(32.4 \%)$ & $628(26.1 \%)$ & $465(26.1 \%)$ & $163(26.0 \%)$ \\
\hline Myocardial infarction & $12(0.7 \%)$ & $8(0.6 \%)$ & $4(0.9 \%)$ & $12(0.5 \%)$ & $8(0.4 \%)$ & $4(0.6 \%)$ \\
\hline
\end{tabular}

STR single-tablet regimen, MTR single-tablet regimen, SD standard deviation, CCI Charlson comorbidity index, HMO health maintenance organization, COMP comprehensive (patients were not incentivized to use a particular list of providers for non-emergency care, and coverage was handled by only one policy)

a Include drugs for lower and upper respiratory infections

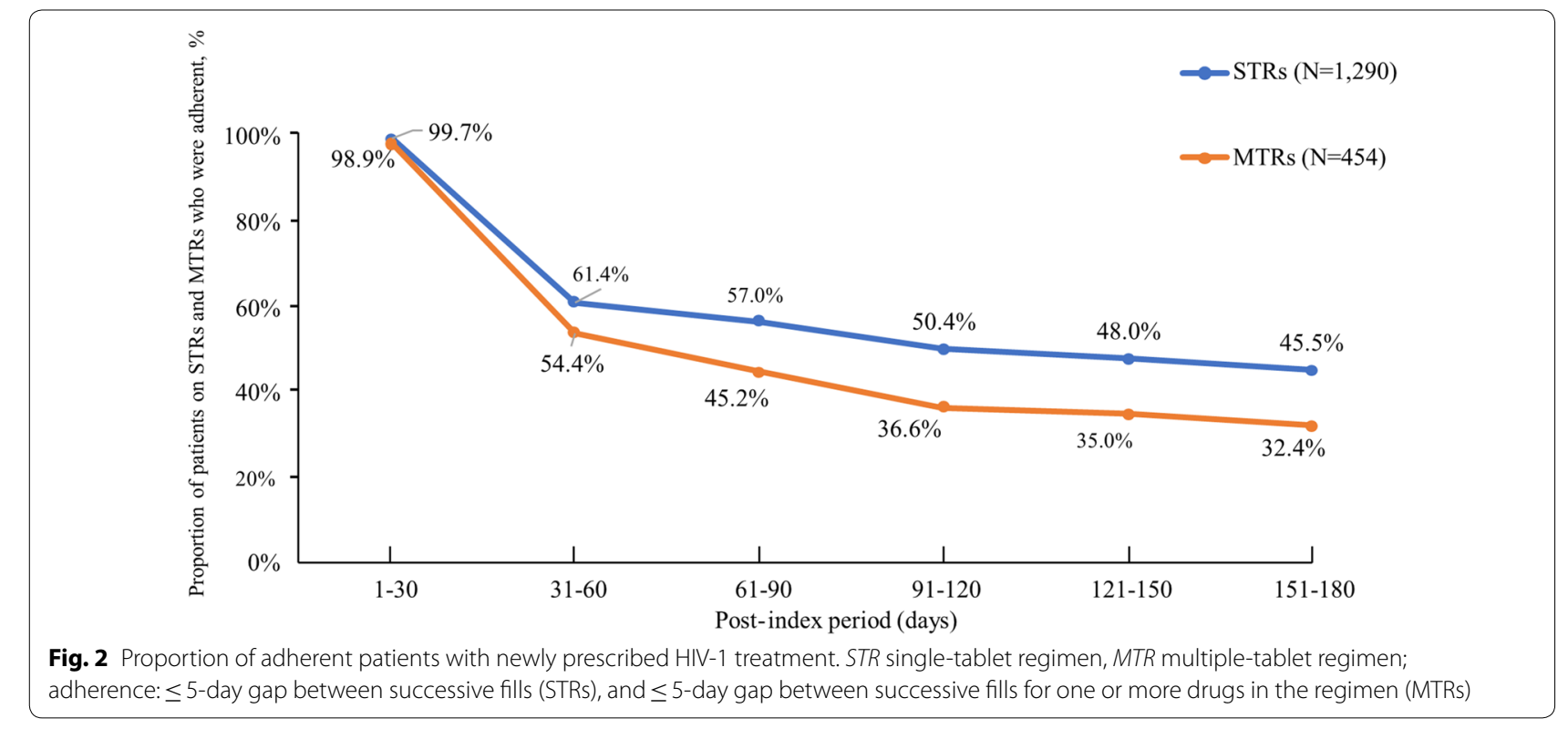

of $>30$ days as compared to STRs (MTRs: 65.6\%; STRs: $53.0 \%)$.

When comparing those initiating STRs, the proportion of patients who were adherent during the post-index period of 1-180 days was highest among patients prescribed EVG/COBI/FTC/TAF (40.7\%) followed by DTG/ ABC/3TC (23.4\%), EVG/COBI/FTC/TDF (22.4\%), RPV/ FTC/TDF (20.8\%), and EFV/FTC/TDF (12.8\%). When comparing patients who were non-adherent, the mean cumulative refill gap for those prescribed STRs was higher among those who initiated EFV/FTC/TDF (80 days) followed by RPV/FTC/TDF (76 days), EVG/COBI/FTC/TDF (70 days), ABC/3TC/DTG (66 days), and EVG/COBI/ FTC/TAF (61 days) (Additional file 1: Figure S1).

Similarly, during the post-index period of 1-180 days, in the MTRs the proportion of adherent patients was highest among patients prescribed DTG + FTC/TDF (17.2\%) followed by DRV/c + FTC/TDF (14.3\%), ATV/c + FTC/
TDF (12.8\%), and DRV/r+FTC/TDF (5.4\%). Furthermore, among patients taking DTG + FTC/TDF, adherence to the DTG component (25.8\%) was more common than to the FTC/TDF component (18.5\%). When comparing patients with MTR who were non-adherent, the mean cumulative refill gap was higher among those who initiated FTC/TDF + DRV/c (91 days), followed by FTC/ $\mathrm{TDF}+\mathrm{ATV} / \mathrm{c}$ (86 days), FTC/TDF + DR/Vr (82 days), and FTC/TDF + DTG (76 days) (Additional file 2: Figure S2).

\section{Sensitivity analysis on STR adherence}

Sensitivity analyses using an adherence definition of $\leq 7$ gap days between successive fills yielded similar adherence rates as the primary definition of $\leq 5$ days. Among the overall patients prescribed STRs, 28.0\% were adherent and $72.0 \%$ were non-adherent during the post-index period of 1-180 days. By STR regimen type, patients prescribed EVG/COBI/FTC/TAF had 
Table 3 Persistence on index treatment among Medicaid beneficiaries newly prescribed ART

\begin{tabular}{|c|c|c|c|}
\hline \multirow[t]{2}{*}{ Persistence assessment } & \multirow{2}{*}{$\begin{array}{l}\text { Number of days } \\
\text { on therapy } \\
\text { Median }\end{array}$} & \multirow{2}{*}{$\begin{array}{l}\text { Patients with 12-month persistence } \\
\text { among those with } 12 \text { months follow-up } \\
\mathrm{N}(\%)\end{array}$} & \multirow{2}{*}{$\begin{array}{l}\text { Patients } \\
\text { with discontinuation } \\
\text { of first-line therapy } \\
\mathrm{N}(\%)\end{array}$} \\
\hline & & & \\
\hline All Regimens (STR + MTR) $[N=2409]$ & 156.0 & $410(43.2 \%)$ & $953(39.6 \%)$ \\
\hline STRs $[N=1782]$ & 166.0 & $313(45.0 \%)$ & $647(36.31 \%)$ \\
\hline $\mathrm{EVG} / \mathrm{COBI} / \mathrm{FTC} / \mathrm{TAF}[\mathrm{N}=274]$ & 145.0 & $8(100.0 \%)^{\dagger}$ & $32(11.7 \%)$ \\
\hline EVG/COBI/FTC/TDF [N=475] & 198.0 & $111(43.4 \%)$ & $224(47.2 \%)$ \\
\hline ABC/3TC/DTG [N = 522] & 180.0 & $106(53.3 \%)$ & $152(21.6 \%)$ \\
\hline $\mathrm{RPV} / \mathrm{FTC} / \mathrm{TAF}[\mathrm{N}=27]$ & 131.0 & $N / A^{a}$ & $0(0.0 \%)$ \\
\hline RPV/FTC/TDF $[N=196]$ & 158.5 & 37 (38.9\%) & $92(46.9 \%)$ \\
\hline EFV/FTC/TDF $[N=288]$ & 140.0 & $51(37.2 \%)$ & $147(51.0 \%)$ \\
\hline MTRs [N=627] & 128.0 & $97(38.0 \%)$ & $306(48.8 \%)$ \\
\hline $\mathrm{ABC} / 3 \mathrm{TC}+\mathrm{DRV} / \mathrm{r}[\mathrm{N}=12]$ & 146.0 & $2(50.0 \%)$ & $3(25.0 \%)$ \\
\hline $\mathrm{FTC} / \mathrm{TDF}+\mathrm{DTG}[\mathrm{N}=205]$ & 151.0 & $32(47.8 \%)$ & $92(44.9 \%)$ \\
\hline $\mathrm{FTC} / \mathrm{TAF}+\mathrm{DTG}[\mathrm{N}=31]$ & 79.0 & $N / A^{a}$ & $0(0.0 \%)$ \\
\hline $\mathrm{FTC} / \mathrm{TDF}+\mathrm{DRV} / \mathrm{r}[\mathrm{N}=184]$ & 119.0 & $34(33.3 \%)$ & $110(59.8 \%)$ \\
\hline $\mathrm{FTC} / \mathrm{TDF}+\mathrm{DRV} / \mathrm{C}[\mathrm{N}=50]$ & 144.0 & $4(30.8 \%)$ & $25(50.0 \%)$ \\
\hline $\mathrm{FTC} / \mathrm{TDF}+\mathrm{ATV} / \mathrm{r}[\mathrm{N}=121]$ & 120.0 & $25(37.3 \%)$ & $71(58.7 \%)$ \\
\hline
\end{tabular}

MTRs including ABC/3TC + DRV/c, FTC/TAF/r/c, FTC/TDF + ATV/c, and FTC/TAF + ATV/r/c were not examined due to the limited sample size

$3 T C$ lamivudine, $A B C$ abacavir, ATV atazanavir, ATV/C atazanavir boosted with cobicistat, ATV/r atazanavir boosted with ritonavir, COBI cobicistat, DRV darunavir, DRV/r darunavir boosted with ritonavir, DRV/c darunavir boosted with cobicistat, DTG dolutegravir, EFV efavirenz, EVG elvitegravir, FTC emtricitabine, MTR multi-tablet regimen, $R P V$ rilpivirine, STR single tablet regimen, TAF tenofovir alafenamide fumarate, TDF tenofovir disoproxil fumarate

a EVG/COBI/FTC/TAF was approved by the FDA in November 2015, RPV/FTC/TAF was approved March 2016, and FTC/TAF was approved April 2016, thus limiting the number of patients with 12 months of follow-up

b Age groups (18-34 years, 35-49 years, 50-64 years and $\geq 65$ years), gender (female and male), race (White, Black, Hispanic and other), insurance type (HMO and COMP), baseline clinical comorbidities (central nervous system toxicity, gastrointestinal symptoms, mental disorders, AIDS-defining condition, substance abuse, jaundice, dyslipidemia, diabetes, chronic kidney disease, cardiovascular disease and myocardial infarction), pre index medication use (antihypertensive, antidiabetics, anticoagulants, antiarrhythmic drugs, lipid-lowering therapy, antibiotics and respiratory drugs), number of unique medications on index date other than antiretroviral therapy (ART), and Deyo-modified CCl score

the highest adherence during the post-index period of 1-180 days (46.7\%). Likewise, findings based on sensitivity analyses using an adherence definition of $\leq 14$ gap days between successive fills also yielded similar findings. Among the overall patients prescribed STRs, $39.8 \%$ were adherent during the post-index period of 1-180 days. By STR regimen type, patients prescribed EVG/COBI/FTC/TAF had the highest proportion of adherent patients during the post-index period of $1-180$ days $(58.5 \%)$.

\section{Treatment persistence}

The median follow up time was 300 days (range: 4-730 days). Unadjusted analysis for persistence indicated that median time on treatment was significantly higher for patients prescribed STRs as compared to MTRs (166 vs 128 days; log-rank test $\mathrm{p}<0.0001)$. Furthermore, $36.3 \%$ of STR patients discontinued the index regimen compared to $48.8 \%$ of MTR patients (Table 3 ). Comparing STRs, median treatment persistence was higher among patients treated with EVG/COBI/FTC/ TDF (198 days), followed by DTG/ABC/3TC (180 days) and RPV/FTC/TDF (159 days). Because there was no minimum follow-up period required, some regimens, including EVG/COBI/FTC/TAF, RPV/FTC/TAF, and FTC/TAF, were not available during the entire study period, thereby limiting the 12-month persistence assessment. After controlling for baseline differences, discontinuation of the first-line therapy was highest for patients treated with EFV/FTC/TDF (51.0\%) followed by EVG/COBI/FTC/TDF (47.2\%) and RPV/FTC/ TDF (46.9\%). The proportion of patients discontinuing first-line STR therapy was lowest for EVG/COBI/ FTC/TAF (11.7\%). When comparing MTRs, median treatment persistence was higher among patients treated with FTC/TDF + DTG (151 days) followed by $\mathrm{ABC} / 3 \mathrm{TC}+\mathrm{DRV} / \mathrm{r}$ (146 days) and FTC/TDF + DRV/c (144 days). First-line therapy discontinuation was highest for patients treated with $\mathrm{FTC} / \mathrm{TDF}+\mathrm{DRV} / \mathrm{r}$ (59.8\%), followed by FTC/TDF + ATV/r (58.7\%) and FTC/TDF + DRV/c (50.0\%). The proportion of patients discontinuing first-line MTR therapy was lowest for $\mathrm{ABC} / 3 \mathrm{TC}+\mathrm{DRV} / \mathrm{r}$ (25\%), albeit among just 12 patients (Table 3). 


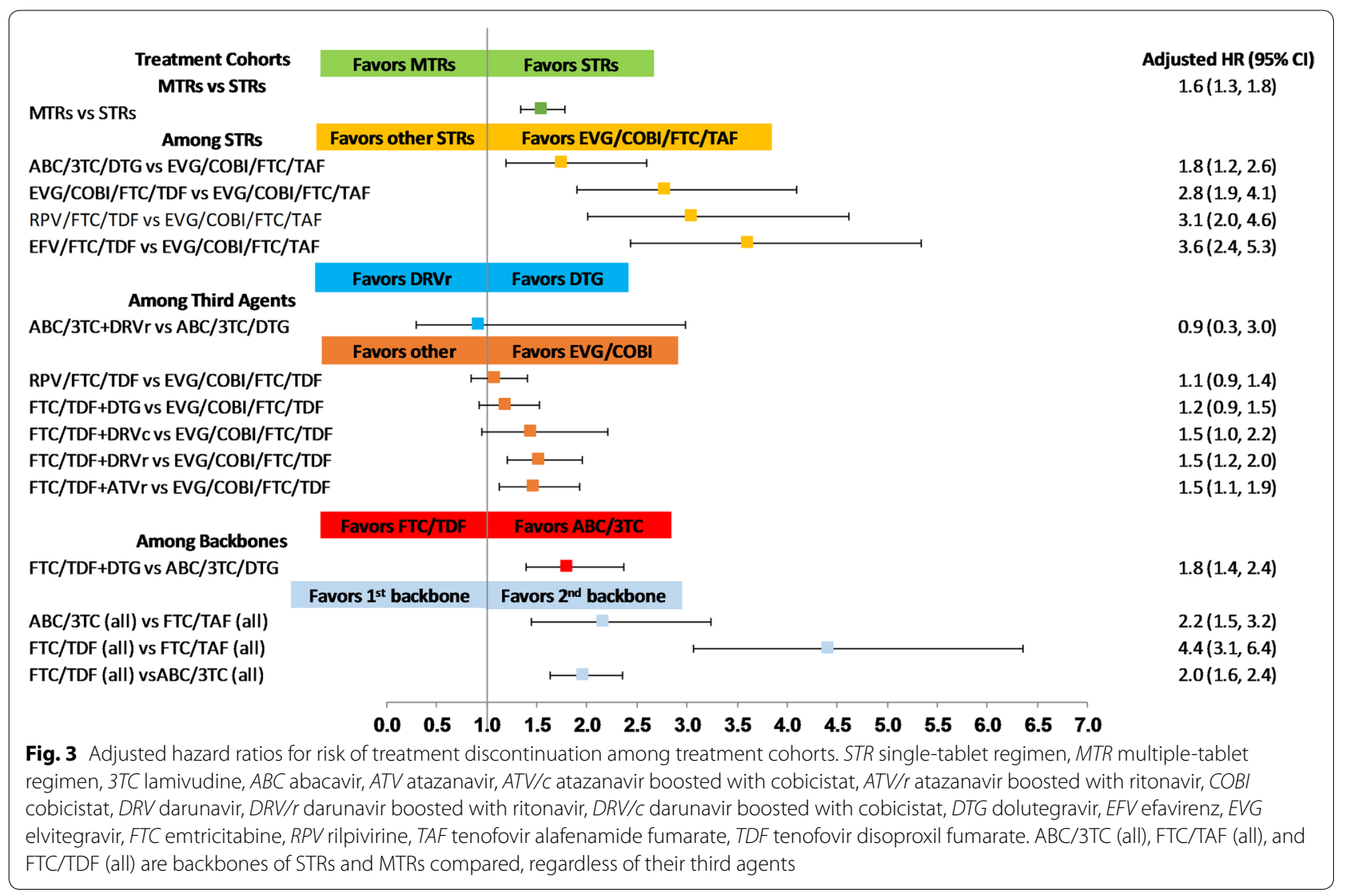

Furthermore, findings from the multivariable Cox proportional hazard model indicated that after controlling for the baseline differences, patients with MTR had a higher risk of treatment discontinuation (HR: 1.6; 95\% confidence interval [CI] 1.3-1.8; $\mathrm{p}<0.0001)$. Similarly, comparing STR patients, persistence was significantly higher for those treated with EVG/COBI/FTC/TAF as compared to EFV/FTC/TDF (HR: 3.6; 95\% CI 2.4-5.3; $\mathrm{p}<0.0001$ ), RPV/FTC/TDF (HR: 3.1; 95\% CI 2.0-4.6; $\mathrm{p}<0.0001$ ), EVG/COBI/FTC/TDF (HR: 2.8; 95\% CI 1.9$4.1 ; \mathrm{p}<0.0001$ ), and DTG/ABC/3TC (HR: $1.8 ; 95 \% \mathrm{CI}$ $1.2-2.6 ; \mathrm{p}=0.004)$.

Comparing third agents, persistence was significantly higher for patients with EVG/COBI use as compared to DRV/r (HR: 1.5; 95\% CI 1.2-2.0; $\mathrm{p}=0.001)$ and ATV/r (HR: 1.5; 95\% CI 1.1-1.9; $\mathrm{p}=0.006$ ) (Fig. 3). Furthermore, when comparing backbones, persistence was significantly higher for patients taking an FTC/TAF-based regimen as compared to an ABC/3TC- (HR: 2.2; 95\% CI 1.5-3.2; $\mathrm{p}<0.0001$ ) or FTC/TDF-based regimen (HR: 4.4; 95\% CI $3.1-6.4 ; \mathrm{p}<0.0001)$, regardless of the third agent. Similarly, the $\mathrm{ABC} / 3 \mathrm{TC}$ backbone was associated with higher persistence compared to FTC/TDF (HR: 2.0; 95\% CI 1.6$2.4 ; \mathrm{p}<0.0001)$, regardless of the third agent.

\section{Discussion}

The discontinuation caused by poor tolerability, poor adherence, or complexity carries risks of the development of toxicity and resistance associated with compromised future treatment options. Improved rates of adherence and persistence are critically important for the long-term therapy of HIV patients [32] and improved health outcomes. In this retrospective claims-based study including several thousand Medicaid recipients newly initiating ART, treatment adherence and persistence were examined and compared among patients prescribed STRs and MTRs.

ART adherence has been shown to improve health outcomes and QoL, including HIV transmission, viral load suppression, drug resistance prevention, and survival rates [4]. Most research examining adherence to ART defines adherence based on either medication possession ratio (MPR) or proportion of days covered (PDC) [27, 33-35]. MPR and PDC are the conventional measure of adherence but are not necessarily the gold standard. The current study's approach of defining adherence as $a<5$ day gap in fills over 30-day intervals during the 6-month follow-up period is more stringent in allowing for examination of the proportion of patients who 
are adherent and non-adherent at different time points from therapy initiation date. The current study found that during the overall 6-month follow-up period, the proportion of adherent patients was higher among STR initiators (22.7\%) compared to MTR initiators (11.7\%); this is similar to the finding from Hines et al., where the same measure of adherence was applied and the proportion of adherent patients for STR initiators and MTR initiators were $24.9 \%$ and $11.7 \%$, respectively [36]. In support of our study, an observational study of 755 people living with HIV recruited from community services found that patients taking STRs were more likely to adhere to their medication compared to those on MTRs [5]. Lowering pill burden is associated with improved adherence and viral suppression, and consequently QoL $[4,37,38]$. In further support of our study findings Sutton et al. showed that an STR cohort had significantly better adherence when compared to an MTR cohort; additionally, risk of hospitalization was lower in the STR cohort [33]. Although our study did not examine barriers to adherence, a study by Chen et al. reported that MTR patients were more likely to report barriers including scheduling, side-effects, and confusion over their prescription as reasons for missing a dose compared to those prescribed STRs [5]. Comparing the STRs, the adherence was highest among those prescribed EVG/COBI/FTC/TAF in contrast to all other STRs.

Adherence and persistence are also considered cornerstones of effective ART therapy; hence, it is recommended that ART regimens should be efficacious, with no virologic failures, well-tolerated, and without toxicity, to improve adherence, and, in turn, improve long-term persistence $[39,40]$. The unadjusted analysis results in the current study show that a lower proportion of STR patients discontinued their first-line therapy (36.3\%) compared to MTR patients (48.8\%). Likewise, the adjusted analysis revealed that MTR patients had a 1.6 times greater hazard of treatment discontinuation as compared to STR patients. In support of this finding, a recent claims-based study among Medicaid beneficiaries also revealed that persistence is greater with less toxic ART regimens that include fewer pills. The study further reported that there was a $29 \%$ reduced hazard of non-persistence with STRs compared with regimens containing $>6$ ART pills per day [41]. Another study also reported that STR discontinuation was lower (i.e., few patients discontinued the STR throughout the study), and further found that patients who switched from an MTR to an STR were able to maintain virologic suppression [14]. Although outside the scope of the current analysis, future research should investigate reasons for discontinuation and switching of therapy. Past research has reported that factors including pill burden, poor tolerability, risk of resistance due to complexity, toxicity, regimen performance, drug efficacy, and virologic failure could be possible reasons for higher rates of discontinuation among MTR patients [20,37, 40]. Furthermore, the current study also showed that among STRs, patients who were treated with EVG/COBI/FTC/TAF had greater persistence compared to those treated with other STRs. Since EVG/COBI/FTC/TAF has been found to have higher efficacy due to fewer drug-related adverse events compared to EVG/COBI/FTC/TDF among treatment naïve patients [42], providers presumably switched regimens based on those data as well as changes to HIV treatment guidelines.

The current study examined regimen components in addition to specific STRs and MTRs. Separate comparisons were performed among patients prescribed third agents and backbones to explicitly explore the benefits derived from each individual component. Our study found that patients who were treated with regimens including an FTC/TAF backbone had higher persistence compared to regimens with $\mathrm{ABC} / 3 \mathrm{TC}$ and $\mathrm{FTC} / \mathrm{TDF}$, providing one of the first real world studies assessing persistence of the FTC/TAF backbone, which was approved in 2016. While reasons for persistence could not be assessed in this analysis, the higher persistence of FTC/TAF likely relates to clinical trial data showing high efficacy and bone and renal safety advantages compared to prior regimens, and the 2018 IAS-USA guidelines recommended TAF but not TDF as a component of initial suggested regimens [43, 44].

The findings from our study should be viewed in the context of study and claims data limitations. While claims data are extremely valuable for the efficient and effective examination of health care outcomes, they are primarily collected for business purposes rather than research purposes. Therefore, analyses may be subject to inherent limitations of the source administrative claims data, such as coding errors or diagnoses entered for administrative processing rather than clinical completeness. Moreover, the presence of a claim for a filled prescription does not indicate that the medication was consumed or taken as prescribed. Also, medications filled over-the-counter or provided as samples by the physician are not observed in claims data. Certain information that could influence study outcomes is not readily available in claims data, such as clinical and disease-specific parameters including HIV viral load, which could be used as a surrogate for adherence. In addition, although the study adjusted for observed baseline characteristics in the multivariable analyses, some unobserved confounders may remain. Further, given the study timeframe, newly-available HIV regimens were not included. Lastly, this study was limited in that health claims may be subject to error; however, given that ART is only used for HIV and that at least 
two ART claims were required for inclusion, it is reasonable to conclude that patients identified in the Truven Medicaid population by ART use are HIV patients.

\section{Conclusions}

In this analysis of real world claims data associated with US Medicaid recipients newly initiating ART, adherence and persistence was greater among patients initiating STRs than those initiating MTRs. In fact, the proportion of patients who were adherent was almost double for those initiating STRs compared to MTRs. Additionally, median treatment persistence was also higher among STR initiators. Regimens containing EVG/COBI as a third agent and FTC/TAF as a backbone showed higher persistence than other third agents and backbones, respectively. In addition, both adherence and persistence were greater with single-tablet EVG/COBI/FTC/TAF than with other STRs. As new regimens with improved safety and tolerability profiles become available, continued research on persistence and adherence for HIV treatments is warranted to inform better therapeutic management.

\section{Supplementary information}

Supplementary information accompanies this paper at https://doi. org/10.1186/s12981-020-00268-1.

Additional file 1: Figure S1. Proportion of Adherent Patients on Individual STRs. 3TC Lamivudine, ABC Abacavir, COBI Cobicistat, DTG Dolutegravir, EVG Elvitegravir, FTC Emtricitabine, RPV Rilpivirine, STR single tablet regimen, TAF Tenofovir Alafenamide Fumarate, TDF Tenofovir Disoproxil Fumarate; Adherence $\leq 5$-day gap between successive fills.

Additional file 2: Figure S2. Proportion of Adherent Patients on Individual MTRs. ATV/c Atazanavir boosted with cobicistat, DRV/c Darunavir boosted with cobicistat, DRV/r Darunavir boosted with ritonavir, DTG Dolutegravir, FTC Emtricitabine, TDF Tenofovir Disoproxil Fumarate; Adherence: $\leq 5$ days gap in fill for one or more drugs in the regimen.

\section{Acknowledgements}

The authors would like to thank Chris Haddlesey of STATinMED Research for editorial assistance of the manuscript. tudy.

Richa Bashyal was affiliated with STATinMED Research at the time of the

\section{Authors' contributions}

$J C, O B, A B, R B, A H$ and JL were involved in study conception, design, interpretation, and critical revisions. RB AH and $J L$ drafted the manuscript and were involved in data acquisition. All authors read and approved the final manuscript.

\section{Funding}

This study was funded by Gilead Sciences Inc.

\section{Availability of data and materials}

The datasets used and/or analyzed during the current study are available from the corresponding author on reasonable request.

\section{Ethics approval and consent to participate}

Since the study herein does not involve the collection, use, or transmittal of individual identifiable data, Institutional Review Board approval was not required.
Consent for publication

All authors have reviewed and approved this manuscript for publication.

\section{Competing interests}

$J C$ and $O B$ have no conflicts to disclose. $A B$ is an employee of Gilead Sciences Inc, the study sponsor. RB, AH, and $J$ are employees of STATinMED Research, a paid consultant to the study sponsor.

\section{Author details}

${ }^{1}$ Tufts University, Boston, MA, USA. ${ }^{2}$ Gilead Sciences Inc, Foster City, CA, USA. ${ }^{3}$ STATinMED Research, Plano, TX, USA. ${ }^{4}$ Columbia University, New York, NY, USA. ${ }^{5}$ University of Michigan, Ann Arbor, MI, USA.

Received: 14 August 2019 Accepted: 20 March 2020

Published online: 01 April 2020

\section{References}

1. Statistics overview. Center of disease control and prevention. 2019. https ://www.cdc.gov/hiv/statistics/overview/index.html. Updated $12 \mathrm{Apr}$ 2019. Accessed 12 Aug 2019.

2. Consolidated guidelines on the use of antiretroviral drugs for treating and preventing HIV infection. World Health Organization. 2016. http:// www.who.int/hiv/pub/arv/arv-2016/en/. Accessed 12 Apr 2018.

3. Broder S. The development of antiretroviral therapy and its impact on the HIV-1/AIDS pandemic. Antiviral Res. 2010;85(1):1-18.

4. Clay PG, Nag S, Graham CM, Narayanan S. Meta-analysis of studies comparing single and multi-tablet fixed dose combination HIV treatment regimens. Medicine. 2015;94(42):e1677.

5. Chen Y, Chen K, Kalichman SC. Barriers to HIV medication adherence as a function of regimen simplification. Ann Behav Med. 2017;51(1):67-78.

6. Panel on Antiretroviral Guidelines for Adults and Adolescents. Guidelines for the use of antiretroviral agents in adults and adolescents living with HIV. Department of Health and Human Services. 2019. https://aidsinfo. nih.gov/contentfiles/lvguidelines/AdultandAdolescentGL.pdf. Accessed 15 Mar 2019.

7. Guidelines for the use of antiretroviral agents in adults and adolescents living with HIV. AIDS Info. 2018. https://aidsinfo.nih.gov/guidelines/ html/1/adult-and-adolescent-arv-guidelines/11/what-to-start. Accessed 12 Apr 2018.

8. Sax PE, Meyers JL, Mugavero M, Davis KL. Adherence to antiretroviral treatment and correlation with risk of hospitalization among commercially insured HIV patients in the United States. PLoS ONE. 2012;7(2):e31591.

9. Catz SL, Kelly JA, Bogart LM, Benotsch EG, McAuliffe TL. Patterns, correlates, and barriers to medication adherence among persons prescribed new treatments for HIV disease. Health Psychol. 2000;19(2):124-33.

10. Llibre JM, Clotet B. Once-daily single-tablet regimens: a long and winding road to excellence in antiretroviral treatment. AIDS Rev. 2012;14(3):168-78.

11. Ing EC, Bae JW, Maru DS, Altice FL. Medication persistence of HIV-infected drug users on directly administered antiretroviral therapy. AIDS Behav. 2013;17(1):113-21.

12. HIV drug chart. POZ. https://www.poz.com/drug_charts/hiv-drug-chart. Accessed 12 Apr 2018.

13. Altice F, Evuarherhe O, Shina S, Carter G, Beaubrun AC. Adherence to HIV treatment regimens: systematic literature review and meta-analysis. Patient Prefer Adherence. 2019;13:475-90.

14. Armstrong B, Chan DJ, Stewart MJ, Fagan D, Smith D. Single tablet regimen usage and efficacy in the treatment of HIV infection in Australia. AIDS Res Treat. 2015;2015:570316.

15. Tarrier L, Kegg S. Who gets single tablet regimens (STR), and why? J Int AIDS Soc. 2014;17(4 Suppl 3):19777.

16. Cohen CJ, Meyers JL, Davis KL. Association between daily antiretroviral pill burden and treatment adherence, hospitalisation risk, and other healthcare utilisation and costs in a US Medicaid population with HIV. BMJ Open. 2013:3(8):e003028.

17. Sutton SS, Magagnoli J, Hardin JW. Odds of viral suppression by singletablet regimens, multiple-tablet regimens, and adherence level in 
HIV/AIDS patients receiving antiretroviral therapy. Pharmacotherapy. 2017;37(2):204-13.

18. Holtzman CW, Shea JA, Glanz K, Jacobs LM, Gross R, Hines J, et al. Mapping patient-identified barriers and facilitators to retention in HIV care and antiretroviral therapy adherence to Andersen's Behavioral Model. AIDS Care. 2015;27(7):817-28.

19. Sweet D, Song J, Zhong Y, Signorovitch J. Real-world medication persistence with single versus multiple tablet regimens for HIV-1 treatment. J Int AIDS Soc. 2014;17(4 suppl 3):19537.

20. Lewis JM, Smith C, Torkington A, Davies C, Ahmad S, Tomkins A, et al. Real-world persistence with antiretroviral therapy for HIV in the United Kingdom: a multicentre retrospective cohort study. J Infect. 2017;74(4):401-7.

21. DeJesus E, Rockstroh JK, Henry K, Molina JM, Gathe J, Ramanathan S, et al. Co-formulated elvitegravir, cobicistat, emtricitabine, and tenofovir disoproxil fumarate versus ritonavir-boosted atazanavir plus co-formulated emtricitabine and tenofovir disoproxil fumarate for initial treatment of HIV-1 infection: a randomised, double-blind, phase 3, non-inferiority trial. Lancet. 2012;379(9835):2429-38.

22. Davy-Mendez T, Eron JJ, Zakharova O, Wohl DA, Napravnik S. Increased persistence of initial treatment for HIV infection with modern antiretroviral therapy. J Acquir Immune Defic Syndr. 2017;76(2):111-5.

23. Snedecor SJ, Radford M, Kratochvil D, Grove R, Punekar YS. Comparative efficacy and safety of dolutegravir relative to common core agents in treatment-naïve patients infected with HIV-1: a systematic review and network meta-analysis. BMC Infect Dis. 2019;19(1):484.

24. Cihlar T, Fordyce M. Current status and prospects of HIV treatment. Curr Opin Virol. 2016;18:50-6.

25. Sax PE, Tierney C, Collier AC, Fischl MA, Mollan K, Peeples L, et al. Abacavirlamivudine versus tenofovir-emtricitabine for initial HIV-1 therapy. N Engl J Med. 2009:361:2230-40.

26. General equivalence mappings: ICD-9-CM to and from ICD-10-CM and ICD-10-PCS. Centers for Medicare \& Medicaid Service. 2009. https://www. cms.gov/Medicare/Coding/ICD10/downloads/ICD-10_GEM_fact_sheet pdf. Accessed 20 Dec 2017

27. Sutton SS, Hardin JW, Bramley TJ, D'Souza AO, Bennett CL. Single-versus multiple-tablet HIV regimens: adherence and hospitalization risks. Am J Manag Care. 2016;22(4):242-8.

28. Levi-Minzi MA, Surratt HL. HIV stigma among substance abusing people living with HIV/AIDS: implications for HIV treatment. AIDS Patient Care STDs. 2014;28(8):442-51.

29. Sweeney SM, Vanable PA. The association of HIV-related stigma to HIV medication adherence: a systematic review and synthesis of the literature. AIDS Behav. 2016;20(1):29-50.

30. Chesney MA, Ickovics JR, Chambers DB, Gifford AL, Neidig J, Zwickl B, Wu AW, et al. Self-reported adherence to antiretroviral medications among participants in HIV clinical trials: the AACTG adherence instruments. AIDS Care. 2000;12(3):255-66.

31. Bardeguez AD, Lindsey JC, Shannon M, Tuomala RE, Cohn SE, Smith E, et al. Adherence to antiretrovirals among US women during and after pregnancy. J Acquir Immune Defic Syndr. 2008;48(4):408-17.
32. Raffi F, Yazdanpanah Y, Fagnani F, Laurendeau C, Lafuma A, Gourmelen J. Persistence and adherence to single-tablet regimens in HIV treatment: a cohort study from the French National Healthcare Insurance Database. J Antimicrob Chemother. 2015;70(7):2121-8.

33. Scott Sutton S, Magagnoli J, Hardin JW. Impact of pill burden on adherence, risk of hospitalization, and viral suppression in patients with HIV infection and AIDS receiving antiretroviral therapy. Pharmacotherapy. 2016;36(4):385-401.

34. Clay PG, Yuet WC, Moecklinghoff CH, Duchesne I, Tronczyński KL, Shah S, et al. A meta-analysis comparing 48-week treatment outcomes of single and multi-tablet antiretroviral regimens for the treatment of people living with HIV. AIDS Res Ther. 2018;15(1):17.

35. Kangethe A, Polson M, Lord TC, Evangelatos T, Oglesby A. Real-world health plan data analysis: key trends in medication adherence and overall costs in patients with HIV. J Manag Care Spec Pharm. 2019;25(1):88-93.

36. Hines DM, Ding Y, Wade RL, Beaubrun A, Cohen JP. Treatment adherence and persistence among HIV-I patients newly starting treatment. Patient Prefer Adherence. 2019:13:1927-39.

37. Nachega JB, Parienti JJ, Uthman OA, Gross R, Dowdy DW, Sax PE, et al. Lower pill burden and once-daily antiretroviral treatment regimens for HIV infection: a meta-analysis of randomized controlled trials. Clin Infect Dis. 2014;58(9):1297-307.

38. Drozd DR, Saag MS, Westfall AO, Mathews WC, Haubrich R, Boswell $\mathrm{SL}$, et al. Comparative effectiveness of single versus multiple tablet antiretroviral therapy regimens in clinical HIV practice. Medicine. 2017;96(14):e6275.

39. Astuti N, Maggiolo F. Single-tablet regimens in HIV therapy. Infect Dis Ther. 2014;3(1):1-17.

40. Jarrin I, Hernández-Novoa B, Alejos B, Riera M, Navarro G, Bernardino Jl, et al. Persistence of novel first-line antiretroviral regimes in a cohort of HIV-positive subjects, CoRIS 2008-2010. Antivir Ther. 2013;18:161-70.

41. Youn B, Shireman TI, Lee Y, Galárraga O, Rana Al, Justice AC, et al. Ten-year trends in antiretroviral therapy persistence among US Medicaid beneficiaries. AIDS. 2017;31(12):1697-707.

42. Imaz A, Podzamczer D. Tenofovir alafenamide, emtricitabine, elvitegravir, and cobicistat combination therapy for the treatment of HIV. Expert Rev Anti Infect Ther. 2017;15(3):195-209.

43. Hagins D, Orkin C, Daar ES, Mills A, Brinson C, DeJesus E, et al. Switching to coformulated rilpivirine (RPV), emtricitabine (FTC) and tenofovir alafenamide from either RPV, FTC and tenofovir disoproxil fumarate (TDF) or efavirenz, FTC and TDF: 96-week results from two randomized clinical trials. HIV Med. 2018;19(10):724-33.

44. Saag MS, Benson CA, Gandhi RT, Hoy JF, Landovitz RJ, Mugavero MJ, et al. Antiretroviral drugs for treatment and prevention of HIV infection in adults: 2018 recommendations of the International Antiviral Society-USA Panel. JAMA. 2018;320(4):379-96.

\section{Publisher's Note}

Springer Nature remains neutral with regard to jurisdictional claims in published maps and institutional affiliations.
Ready to submit your research? Choose BMC and benefit from:

- fast, convenient online submission

- thorough peer review by experienced researchers in your field

- rapid publication on acceptance

- support for research data, including large and complex data types

- gold Open Access which fosters wider collaboration and increased citations

- maximum visibility for your research: over $100 \mathrm{M}$ website views per year

At BMC, research is always in progress.

Learn more biomedcentral.com/submissions 